\title{
Vertebro-Spinal Hydatidosis: Case Report
}

\section{Belhaj K*, Diagne NS, Zahi S, Azanmasso H, Lmidmani F and Fatimi A. El}

Department of Physical Medicine and Rehabilitation, Ibn Rochd University Hospital, Casablanca, Morocco

${ }^{*}$ Corresponding author: Belhaj K, Department of Physical Medicine and Rehabilitation, Ibn Rochd University Hospital, Casablanca, Morocco, E-mail: ducari83@gmail.com

Citation: Belhaj K, Diagne NS, Zahi S, Azanmasso H, Lmidmani F, et al. (2015) Vertebro-Spinal Hydatidosis: Case Report. J Case Rep Stud 3(2): 201. doi: 10.15744/2348-9820.2.501

Received Date: December 23, 2014 Accepted Date: March 27, 2015 Published Date: April 07, 2015

\begin{abstract}
Hydatid disease is caused by the larval form of parasitic tapeworm; Echinococcus granulosus. Primary spinal hydatid disease is rare. Primary bone localization is rare and it accounts between $0.5 \%$ and $4 \%$. Spinal localization accounts for less than $1 \%$. The infection may be misdiagnosed initially. Our case was a 39- year-old woman presented with progressive low back pain, intermittent claudication and sphincter disorders type urinary incontinence for 20 days. Neurological examination found a paraparesia and hypoesthesia without superior sensitive level. Magnetic resonance images of the thoracal region showed an intradural multicystic lesion. The mass was explored with D7-L2 laminectomy. Lesion was easily dissected from the cord and was resected totally. The pathological diagnosis was hydatid disease.
\end{abstract}

Keywords: Hydatid disease; Spine; Paraparesis; Albendazole

\section{Introduction}

Hydatid disease is caused by the larval form of parasitic tapeworm; Echinococcus granulosus [1]. It occurs in humans from the contamination of water and foodstuffs most frequently in countries with poor socio-sanitary conditions [2-4]. Hydatid disease can develop anywhere in the human body. Liver, spleen and lung are the most frequently involved organs [5,6]. Primary bone localization is rare and it accounts between $0.5 \%$ and $4 \%$ [7-9]. Spinal localization accounts for less than $1 \%$ of all hydatid disease [7]. The authors report a case of a young woman admitted for progressive paraparesia secondary to primary vertebra-spinal hydatidosis.

\section{Case report}

A 39 year-old Moroccan woman with a history of pleural and hepatic hydatic cyst presented a progressive mechanic low back pain with intermittent claudication and sphincter disorders type urinary incontinence for the last 20 days. Neurological examination found a paraparesia grade 3/5 and hypoesthesia without superior sensitive level. Magnetic resonance imagery (MRI) showed an intradural extramedullary multicystic lesion with a regular contour at level D7-L2. The lesion gave a low signal on T1-weighted and high signal on T2-weighted images and demonstrated a circumferential low enhancement after contrast material injection (Figure 1 and 2). The spinal cord and cauda equina were compressed. Hydatid serology by using ELISA test was positive. There was a high level of eosinophil blood cells $\left(700 / \mathrm{mm}^{3}\right)$. Further explorations were normal without any other localization.

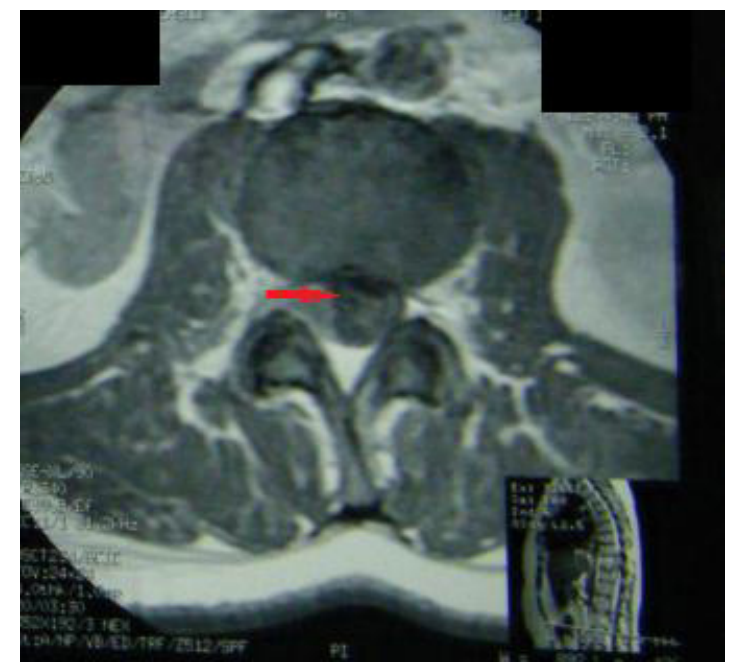

Figure 1: MRI Axial T1 at the $11^{\text {th }}$ vertebra showed spinal hydatidosis 


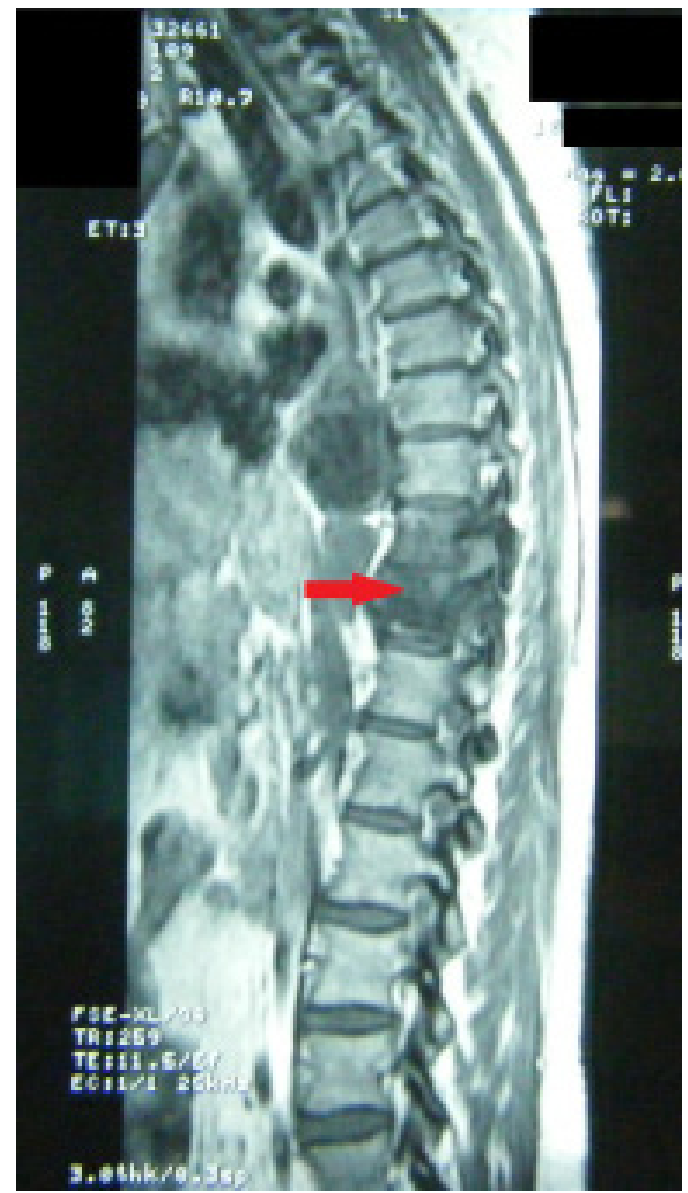

Figure 2: MRI Sagittal section objectifying multicystic formations and pre latero-vertebral extent of the $7^{\text {th }}$ vertebra

The patient underwent surgery to excise the cysts and had a laminectomy performed through the posterior approach for neurologic decompression at the level of spinal involvement (D7-L2). Care was taken to prevent rupture while removing the cysts. Multiple vesicles were found and easily dissected with total resection from the cord. All the cysts were removed. The operation area was soaked with 3\% normal saline. The surrounding surgical field was packed with mops and iliac autogenous bone grafting was used for reconstruction. Histopathological examination confirmed the diagnosis of hydatid cyst. Antihelminthic therapy with $400 \mathrm{mg}$ of albendazole 3 times daily was prescribed for 6 months then followed by low dose for 6 months of maintenance. Radiological evaluation showed no evidence of disease recurrence. Postoperative neurological rehabilitation was performed for 6 months. Patient had normal neurologic status at the last follow-up of one year. At the end of the treatment (1 year), hydatid serology and blood Eosinophilia were normal.

\section{Discussion}

Hydatid disease caused by the larval stage of the cestode Echinococcus granulosus which is a cosmopolitan parasitic zoonosis. In the accidental human intermediate host, the liver and lungs have been predominantly concerned (90\%) [10,11]. Bone affection is rare (0.5-4\%); spine is involved in half of the cases [10]. Thoracic spine is most generally affected in $52 \%$, followed by lumbar in $37 \%$, sacral and cervical in $5.5 \%$ each one $[12,13]$. Primary vertebral hydatid disease can occur if there are direct porto-vertebral venous shunts [14].

Spinal cystic echinococcosis is associated with high degree of morbidity and mortality. It is classified into five groups [7,15-17]:

- Primary intramedullary cyst;

- Intradural extra medullary cyst;

- Extradural intraspinal cyst;

- Vertebral body disease;

- Paravertebral cyst.

In the literature one-third of the patients had previously undergone surgery for their cysts [7]. Our patient had a history of pulmonary and hepatic cyst resection. Vertebral and spinal cord hydatidosis is preceded by a long history of back pain. There isn't specific symptoms, it may manifest with any symptom related to vertebral bone destruction or spinal cord compression as radicular pain, peripheral sensitivity loss, sphincter disturbance, bladder dysfunction, paraparesis, paraplegia [1,18-22]. In our patient the neurological examination found paraparesia. 
On plain radiographs and in the advance stage, there was bone destruction. CT scan with IV contrast does not show any enhancement. It provides a precise anatomic localization with assessment of the osseous part of the lesion, the extension into the soft tissues, and the calcifications of the peripheral rim of the cyst, if they exist [23-25]. MRI technique is the method of choice. It is superior to CT scan for demonstrating neural involvement [26,27]. The presence of a hypointense cyst wall on T1- and T2weighted images is characteristic of hydatidosis [14]. Computed tomography and MRI examinations determine the extent of the lesion, the relation to the spinal canal, and the preoperative planning of the surgical approach to hydatid cyst.

Surgery is the treatment of choice with removal of all cyst contents without contaminating the patient [21]. Usually, posterior spinal decompression through laminectomy and debridement of paravertebral lesions is the initial surgery [21,28]. The surgical area might be irrigated with chemical agents (3\% normal saline) in an attempt to kill scoleces [14,16]. Reconstruction is performed according to the degree of substance loss. Besides surgery, the only other treatment option for vertebral and spinal cord hydatidosis is antiparasitic therapy (albendazole); surgery with concomitant antiparasitic became the treatment standard [29]. Efficacy of albendazole for primary bony hydatid involvement is questionable; postoperative albendazole therapy seems only to retard recurrence $[21,30,31]$. In this case, the patient received albendazole for one year without recurrence.

\section{Conclusion}

Despite significant advances in diagnostic imaging techniques and surgical treatment, spinal hydatisosis remains associated with a high degree of morbidity, disability and mortality. The infection may be misdiagnosed initially as tuberculosis of the spine. Surgery is the treatment of choice with decompression of a compromised spinal cord. Besides surgery, the association of albendazole is currently considered the treatment standard. High recurrence rates remain the great problem, especially in cases with vertebral bone involvement.

\section{References}

1. Pamir MN, Ozduman K, Elmaci I (2002) Spinal hydatid disease. Spinal Cord 40: 153-60.

2. Wilkins RH, Rengachary SS, Neurosurgery (Vol 3) McGraw-Hill Book Company, New York, USA.

3. Sze G (1988) Infections and inflammatory diseases. In: Stark DD, Bradley WG, editors. Magnetic Resonance Imaging. The C V Mosby Company, St Louis, Washington DC: 322.

4. Schnepper GD, Johnson WD (2004) Recurrent spinal hydatidosis in North America. Case report and review of the literature. Neurosurg Focus 17: E8.

5. Chatterjee KD (1995) Textbook of Parasitology (12 $2^{\text {th }}$ edn) Calcutta, India. Chatterjee Medical Publications.

6. Desai HJ, Bhatt CJ, Dave BA (1999) Images - Primary spinal echinococcosis. Ind J Radiol Imag 9: 73-6.

7. Pamir MN, Akalan N, Ozgen T, Erbengi A (1984) Spinal hydatid cysts. Surg Neurol 21: 53-7.

8. Polat P, Kantarci M, Alper F, Suma S, Koruyucu MB, et al. (2003) Hydatid disease from head to toe. Radiographics 23: 475-94.

9. Torricelli P, Martinelli C, Biagini R, Ruggieri P, De Cristofaro R (1990) Radiographic and computed tomographic findings in hydatid disease of bone. Skeletal Radiol 19: 435-9.

10. Moharamzad Y, Kharazi HH, Shobeiri E, Farzanegan G, Hashemi F, et al. (2008) Disseminated intraspinal hydatid disease. J Neurosurg Spine 8: 490-3.

11. Ozdemir HM, Ogün TC, Tasbas B (2004) A lasting solution is hard to achieve in primary hydatid disease of the spine: Long term results and an overview. Spine (Phila Pa 1976) 29: 932-7.

12. Rao AJ, Gultekin SH, Neuwelt EA, Cintrón-Colón HR, Ragel BT (2011) Late occurrence of drop metastasis to the spine in a case of esthesioneuroblastoma. J Neurosurg Spine 15: 571-5.

13. Akhan O, Dinçer A, Saatçi I, Gülekon N, Besim A (1991) Spinal intradural hydatid cyst in a child. Br J Radiol 64: 465-6.

14. Awasthy N, Chand K (2005) Primary hydatid disease of the spine: An unusual case. Br J Neurosurg 19: 425-7.

15. Ogut AG, Kanberoglu K, Altug A, Cokyuksel O (1992) CT and MRI in hydatid disease of cervical vertebrae. Neuroradiology 34: 430-2.

16. Pushparaj K, Sundararajan M, Madeswaran K, Ambalavalan S (2001) Primary spinal intradural hydatid cyst. Neurol India 49 : $203-4$.

17. Sharma NK, Chitkara N, Bakshi N, Gupta P (2003) Primary spinal extradural hydatid cyst. Neurology India 51: 89-90.

18. Limaiem F, Bellil S, Bellil K, Chelly I, Mekni A, et al. (2010) Primary hydatidosis of the central nervous system: a retrospective study of 39 Tunisian cases. Clin Neurol Neurosurg 112: 23-8.

19. Altinors N, Bavbek M, Caner HH, Erdogan B (2000) Central nervous system hydatidosis in Turkey: a cooperative study and literature survey analysis of 458 cases. J Neurosurg 93: 1-8.

20. Turgut M (1997) Hydatid disease of the spine: a survey study from Turkey. Infection 25: 221-6.

21. Islekel S, Ersahin Y, Zileli M, Oktar N, Oner K, et al. (1998) Spinal hydatid disease. Spinal Cord 36: 166-70.

22. Herrera A, Martinez AA, Rodriguez J (2005) Spinal hydatidosis. Spine (Phila Pa 1976) 30: 2439-44.

23. Braithwaite PA, Lees RF (1981) Vertebral hydatid disease: radiological assessment. Radiology 140:763-6.

24. Bouras A, Ladré D, Mathieu D, Délepine G, Benameur C, et al. (1984) The value of computed tomography in osseous hydatid disease (Ecchinococcosis). Squeletal radiology. 12: 192-5.

25. Helenon O, Folinais D, David M, Blangy S, Sibert A, et al. (1986) Osseous hydatidosis of the pelvic girdle. Contribution of computerized tomography and ultrasonics. Apropos of 3 cases. J Radiol 67: 515-21.

26. Taourel P, Marty-Ane B, Charasset S, Mattei M, Devred P, et al. (1993) Hydatid cyst of the liver; comparison of CT and MRI. J Comput Assist Tomogr 17: 80-5. 
27. Pedrosa I, Saiz A, Arrazola J, Ferraires J, Pedroza CS (2000) Hydatid disease: radiological and pathological features and complications. Radiographics 20: 795817.

28. Fares Y, Khazim R, El Zaatari MM, Haddad GF, Bannes PR (2003) Spinal hydatid disease and its neurological complications. Scand J Infect Dis 35: 394-6.

29. Berk C, Ciftci E, Erdogan A (1998) MRI in primary intraspinal extradural hydatid disease: Case report. Neuroradiology 40: $390-2$.

30. Mazyad MA, Morsy TA, Habib KS (1991) Vertebral unilocular hydatidosis in a shepherd and his wife. J Egypt Soc Parasitol 29: 547-50.

31. Normalli HC, Aaro SI, Follin PH (1988) Vertebral hydatid cyst infection (Echinococcus granulosus) a case report. Eur Spine J 7: 158-61.

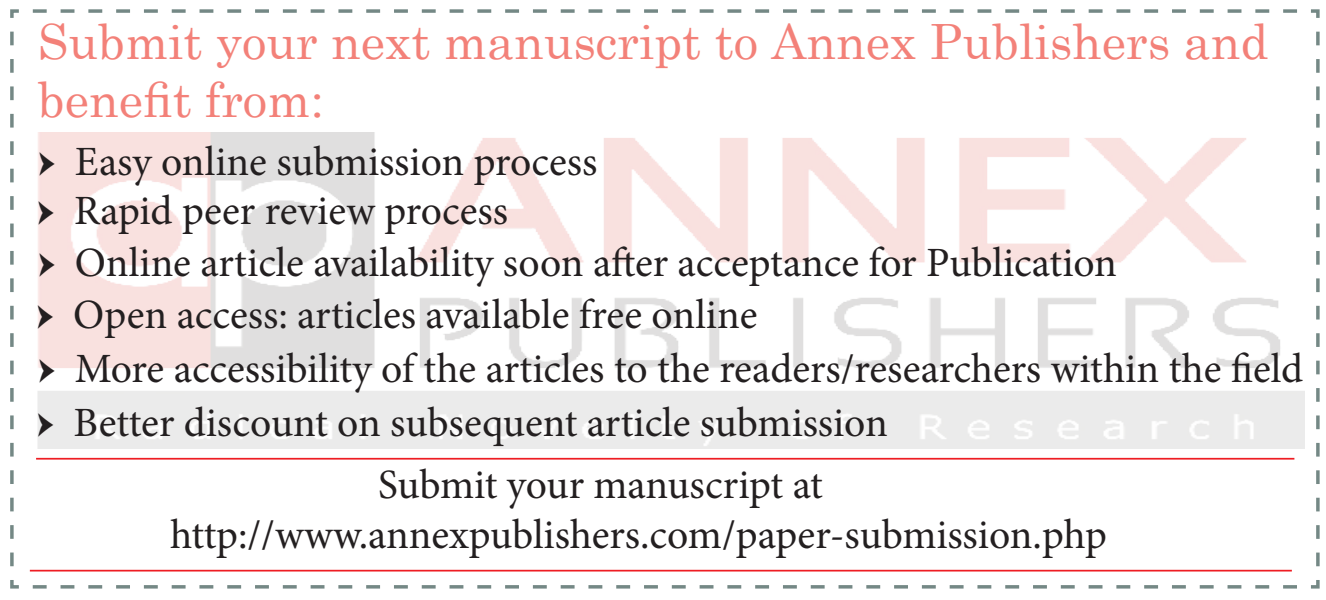

